\title{
Virtual Heritage: From Archives to Joysticks
}

\author{
Erik Malcolm Champion \\ Curtin University; ANU; UWA \\ erik.champion@curtin.edu.au
}

While virtual heritage was initially described as a fusion of virtual reality (VR) technology with cultural heritage content (Addison 2001; Roussou 2002), as VR keeps changing, preservation of the content becomes increasingly problematic. Virtual heritage has been a (sometimes) successful communication medium but seldom has it succeeded as a preservation medium (Champion 2016).

Even the term virtual reality has been used loosely, while the terms augmented reality and mixed reality may transform into more overarching terms like XR (extended reality), or merged reality.

Stone and Takeo further emphasized the educational aspect (R. Stone \& Ojika 2000):

... the use of computer-based interactive technologies to record, preserve, or recreate artifacts, sites and actors of historic, artistic, religious, and cultural significance and to deliver the results openly to a global audience in such a way as to provide formative educational experiences through electronic manipulations of time and space.

I have previously suggested that the purpose and significance of virtual heritage (Champion 2006) is more clearly defined as:

the attempt to convey not just the appearance but also the meaning and significance of cultural artefacts and the associated social agency that

How to cite this book chapter:

Champion, E. M. 2021. Virtual Heritage: From Archives to Joysticks. In: Champion, E. M. (ed.) Virtual Heritage: A Guide. Pp. 5-11. London: Ubiquity Press. DOI: https: //doi.org/10.5334/bck.b. License: CC-BY-NC 
designed and used them, through the use of interactive and immersive digital media.

If we follow the above definitions, then virtual heritage is not only the bringing together of virtual reality technology with cultural heritage content, it is also an experiential medium. However, that experience is based on the recreating or reconstructing of data, measurements, and observations.

Virtual heritage is a fascinating and challenging area of practice and research, but papers seldom examine underlying assumptions and precepts or explain the complete design and testing process. Where academic work is published, it is typically behind paywalls. Where are the primers providing an overview of immersive technology applied to cultural heritage, directly and conveniently accessible to the public? And where does one learn to make the leap from measurement to user experience?

Unlike other fields, virtual heritage projects are seldom long-lived and robust, clear and significant results are hard to find, data is seldom shared or easily accessible. Because of the many fields that help develop and present virtual heritage projects and related technology, the lack of access to past projects and results, and the manic changes in related technologies, students and scholars from other fields face steep learning curves regards the technical opportunities, the interaction design challenges, and the preservation risks. Our solution was to create a guide that is more concise, applied, and accessible to students from related fields. This is a key reason why this book is available as an open access publication.

\section{Measurement}

In the first chapter, Chapter 1: Speculating the Past: 3D Reconstruction in Archaeology, Robert Barratt explains the relationship between virtual heritage as discipline and as argument. To be an effective scholarly medium, virtual heritage requires precision (because of its underlying computational nature), but also a way to convey the reasoning behind the measuring, the decision making informing the design of the simulations and conjectural models.

Given that measurement is important, the interesting thing about measurement is how we learn from how we and others measure. The next chapter, by Hafizur Rahaman, Chapter 2: Photogrammetry: What, How, and Where, explains the increasing importance and versatility of photogrammetry. The timeconsuming process of $3 \mathrm{D}$ model making can be replaced by photogrammetry, leaving us time to experiment with designing better user experiences. Interestingly, photogrammetry can work on personal devices or leverage supercomputers.

From the camera arises the 3D model, but how do we give the $3 \mathrm{D}$ model life? Through representation and interaction, perhaps we could represent how these people understood and represented their world to each other. Animation and 
modellings are key elements to producing captivating virtual environments, and there is now a range of impressive but free and open source software. In Chapter 3: Animating Past Worlds, William Carter explains how advances in animation as technology, discipline, and art can augment and improve the field of virtual heritage.

However, there are two forms of measurement here: measurement of what has been left behind, and conveying the contextual measurement of what was built, created, and shared by the original peoples themselves - how did they measure and value elements of their culture? How did they map what they measured and why it was worth measuring? How could we communicate this to people today? The authors of Chapter 4: Mapping Ancient Heritage with Digital Tools explain how ancient concepts of place and journey can inform current initiatives to map past worlds.

\section{Interaction}

The above chapters have touched on interaction but are fundamentally concerned with visualisation based on measurement. The next group of essays focuses on the role of interaction in virtual heritage. Despite the promise and excitement of technological showcases, this is still a problematic component of virtual heritage. For instance, Roussou and Slater (2005) decried the current state of meaningful interaction and learning in virtual reality:

Hence, the research question that emerges is how interactivity in a virtual learning environment can influence learning.

Museums and galleries are ideal environments for interactive virtual heritage, but they seldom have the resources (Birchall \& Ridge 2015) to fund full-time guided teaching and interactive-learning experiences; many may even lack space to display all of their collections (Bradley 2015). Hurt by the Coronavirus pandemic and drastic cuts in staffing and overall funding, they require robust, flexible, long-term technology.

How do we address the challenges of museums and the wider GLAM sector, but also leverage their great virtues: as meeting places and as havens for education and edification? In Chapter 5: Hybrid Interactions in Museums: Why Materiality Still Matters, Luigina Ciolfi explains how hybrid interaction can bridge the gap between technological showcases and the direct person-to-person virtues of the museum space.

Perhaps we can also look to related industries for collaborative funding and development. For example, the video game industry is hugely profitable; Juniper Research predicted that worldwide it would surpass 100 billion dollars in revenue in 2017 (Graham 2017). Commercial game studios can spend millions on capturing $3 \mathrm{D}$ digital assets and animating captivating environments. Their 
allure and influence on virtual heritage is considerable, but their potential collaboration is vastly more significant.

In archaeology, there have been recent investigations of 'archaeogaming, defined as 'the archaeology in and of video games' (Aycock \& Reinhard 2017). Designers are moving away from the principal goal of photo-realism, towards the potential of interpretation and conceptual learning (Roussou 2005). Gaming can be highly sophisticated or designed with primitive blocks by school children (such as Minecraft). In Chapter 6: Video Games as Concepts and Experiences of the Past, Aris Politopoulos and Angus Mol describe their teaching and research projects on archaeogaming and how this popular entertainment medium can also be educational.

We might primarily consider virtual heritage to be only virtual reality, but mixed reality and augmented reality offer several advantages over virtual reality. Virtual reality (VR) is typically custom built and expensive for the general public, requiring specialist technology experts and facilities that are expensive, hard to source (Carrozzino \& Bergamasco 2010), and difficult to maintain by specialist but cash-strapped heritage organizations such as galleries, libraries, museums (Ridge \& Birchall 2015), let alone by the general public or shareholder communities.

A possible solution is to employ mixed reality, augmented reality, or consumerlevel virtual reality. In recent years, there have been increasing synergies between video games and virtual reality, thanks to increasingly powerful computers and the development of consumer-priced head-mounted displays (HMDs), see-through mixed reality HMDs, and smart-phone based augmented reality systems. In Chapter 7: Mixed Reality: A Bridge or a Fusion between Two Worlds? Mafkereseb Bekele explores whether mixed reality is an experience or a technology and how it can help bridge the past and the present.

Interaction requires an audience, and mixed reality in virtual heritage, arguably, has not yet fully leveraged the engagement and value of participative contexts.

\section{Ethics and Evaluation}

The last section outlines key issues in virtual heritage evaluation. However, before we set up our questionnaires and experimental designs, there are key ethical issues in cultural heritage and digital archaeology that need to be addressed but are seldom covered. In Chapter 8: Getting It Right and Getting It Wrong in Digital Archaeological Ethics, Meghan Dennis explains how technology is not morally neutral: there are successful projects that 'get it right', but we can also learn from failed projects that 'get it wrong'.

Inadequate interactivity or a lack of reflection on related ethical and moral issues can lead to uncertain pedagogical benefits. In virtual heritage, arguably, evaluations are usually not conducted on the intended final audience, and the 
experimental designs cannot be found or repeated by others. Although there are charters such as the London Charter and the Seville Charter, there are few publicly accessible models, and we lack a shared standardized evaluation dataset. In Chapter 9: Evaluation in Virtual Heritage, Panayiotis Koutsabasis explains the many evaluation methods available to virtual heritage, why it is a great field for user experience design, and criteria for ensuring a successful virtual heritage project.

That is not to suggest virtual heritage has many examples exhibiting exemplary usability or usefulness. Many researchers have complained about user experience issues and a scarcity of suitable pedagogical material (Karoulis, Sylaiou \& White 2006) or the scarcity of data, collections and projects conveying the accuracy, authenticity and authorship of the simulated material (De Reu et al. 2012).

Neither virtual heritage software nor commercial games are currently flexible enough to quickly and simply handle various content, nor do the models have real-time capability to link to scholarly publications and crowd-sourced material; hence many are stillborn (Guidazzoli et al. 2016).

For example, (R. J. Stone, 2005) remarked:

...VR delivered very little of use to the global IT community. A handful of organisations actually adopted VR, but most were deterred from doing so by its complexity and cost. Today's VR supply companies have either passed away or are hanging on by a thread.

There are too few successful and popular projects that people can find, access, and simply make work again (Economou \& Pujol 2008). Many have simply disappeared or are only communicated via academic conference papers. For example, Thwaites (2013) recently warned that 'We cannot afford to have our digital heritage disappearing faster than the real heritage or the sites it seeks to "preserve" otherwise all of our technological advances, creative interpretations, visualizations and efforts will have been in vain.'

There are major problems encountered when preserving cultural heritage in physical museums (Michaelis, Jung \& Behr 2012), and the reliability of 3D data for long-term preservation is an on-going issue. However, one way of approaching the issues of preservation - and it is not yet a mainstream one - is to approach the challenges of preservation through rethinking the challenge of authenticity. If virtual heritage is based on digital capture and digital creation, what is authentic? How are we trying to understand and preserve cultural authenticity when we employ digital technology? Why do so many projects in digital heritage avoid tackling the related issue of authenticity? And if they are not authentic (in some way), why do they deserve to be preserved?

In the final chapter, Chapter 10: Authenticity and Preservation, I briefly try to explain this linked challenge and offer some potential short and longterm solutions. 


\section{Conclusion}

Virtual heritage is not yet a dependable and demonstratively effective communication medium; there are still too few examples of accessible useful and engaging models that one can test, verify, experience, and learn from. The field is in serious need of more contextual and useful usability research, but the biggest issue is arguably preservation of the research data and 3D models.

\section{References}

Addison, A C 2001, 28-30 November 2001 Virtual Heritage: Technology in the service of culture. Paper presented at the Proceedings of the 2001 conference on Virtual reality, archeology, and cultural heritage, Athens, Greece.

Aycock, J and Reinhard, A 2017 Copy Protection in Jet Set Willy: Developing methodology for retrogame archaeology. Internet Archaeology, 45. DOI: https://doi.org/10.11141/ia.45.2

Birchall, D and Ridge, M 2015 Post-web technology: What comes next for museums? The Guardian. Retrieved from http://www.theguardian.com /culture-professionals-network/culture-professionals-blog/2014/oct/03 /post-web-technology-museums-virtual-reality

Bradley, K 2015 Why museums hide masterpieces away. BBC Culture. Retrieved from https://www.bbc.com/culture/article/20150123-7-masterpieces-you -cant-see

Carrozzino, M and Bergamasco, M 2010 Beyond virtual museums: Experiencing immersive virtual reality in real museums. Journal of Cultural Heritage, 11(4): 452-458.

Champion, E 2006, 15 March Explorative Shadow Realms of Uncertain Histories. Paper presented at the New Heritage Conference: Cultural Heritage and New Media. Theme: Beyond verisimilitude; interpretation of cultural heritage through new media, University of Hong Kong.

Champion, E 2016 Entertaining the similarities and distinctions between serious games and virtual heritage projects. Entertainment Computing, 14: 67-74. DOI: https://doi.org/10.1016/j.entcom.2015.11.003

De Reu, J, Plets, G, Verhoeven, G, De Smedt, P, Bats, M, Cherretté, B, . . . De Clercq, W 2012 Towards a three-dimensional cost-effective registration of the archaeological heritage. Journal of Archaeological Science, 40(2): 1108-1121. DOI: https://doi.org/10.1016/j.jas.2012.08.040

Economou, M and Pujol, L 2008 Educational tool or expensive toy? Evaluating VR evaluation and its relevance for virtual heritage. New Heritage: New Media and Cultural Heritage, London, Routledge, 242-260.

Graham, L 2017, 15 Feb Digital games market to see sales worth $\$ 100$ billion this year: Research. Retrieved from https://www.cnbc.com/2017/02/15/digital -games-market-to-see-sales-worth-100-billion-this-year-research.html 
Guidazzoli, A, Imboden, S, De Luca, D, Verri, L, Liguori, M C, Bellavia, G, and Baglivo, A 2016 Blender: A framework for cross-media cultural heritage applications. Paper presented at the Proceedings of the 2016 Virtual Reality International Conference.

Karoulis, A, Sylaiou, S, and White, M 2006 Usability evaluation of a virtual museum interface. Informatica, 17(3), 363-380.

Michaelis, N, Jung, Y, and Behr, J 2012 Virtual heritage to go. Paper presented at the Proceedings of the 17th International Conference on 3D Web Technology.

Ridge, M and Birchall, D 2015 How digital tech can bridge gaps between museums and audiences. The Guardian Online. Retrieved from https: //www.theguardian.com/culture-professionals-network/2015/oct/23/digital -technology-museums-audiences-collaboration

Roussou, M 2002 Virtual heritage: From the research lab to the broad public. Bar International Series, 1075: 93-100.

Roussou, M 2005 Can interactivity in virtual environments enable conceptual learning? Paper presented at the 7th Virtual Reality International Conference (VRIC), First International VR-Learning Seminar, Laval, France.

Roussou, M and Slater, M 2005 A virtual playground for the study of the role of interactivity in virtual learning environments. Perspectives, 8(9).

Stone, $\mathbf{R}$ and Ojika, T 2000 Virtual heritage: What next? IEEE Multimedia, 7(2): 73-74.

Stone, R J 2005, 3-7 October Serious Gaming-Virtual Reality's Saviour. Paper presented at the Virtual Systems and MultiMedia annual conference (VSMM 2005), Ghent, Belgium.

Thwaites, H 2013 Digital Heritage: What Happens When We Digitize Everything? In E. Ch'ng, V. Gaffney, \& H. Chapman (Eds.), Visual Heritage in the Digital Age (pp. 327-348). London: Springer. 